\title{
Establishing consensus among interprofessional faculty on a gender- based violence curriculum in medical schools in Nigeria: A Delphi study
}

\author{
O I Fawole, ${ }^{1} \mathrm{MBBS}, \mathrm{MSc}, \mathrm{FNMC}(\mathrm{PH})$, FWACP; J van Wyk, ${ }^{2} \mathrm{PhD}$; A A Adejimi, ${ }^{3} \mathrm{MBBS}, \mathrm{MPH}, \mathrm{FWACP} ; \mathrm{O} \mathbf{J}$ Akinsola, ${ }^{4} \mathrm{BSc}, \mathrm{MSc}, \mathrm{MPhil} ; \mathbf{O}$ Balogun, ${ }^{5} \mathrm{MBBS}, \mathrm{MPH}$ \\ ${ }^{1}$ Department of Epidemiology and Medical Statistics, Faculty of Public Health, College of Medicine, University of Ibadan, Nigeria \\ ${ }^{2}$ Department of Clinical and Professional Practice, Nelson R Mandela School of Medicine, University of KwaZulu-Natal, Durban, South Africa \\ ${ }^{3}$ Department of Community Medicine, College of Medicine, Ladoke Akintola University of Technology, Osogbo, Nigeria \\ ${ }^{4}$ Department of Community Medicine and Primary Health Care, College of Medicine, University of Lagos, Nigeria \\ ${ }^{5}$ Department of Community Medicine, College of Medicine, University of Ibadan, Nigeria
}

Corresponding author: O I Fawole (fawoleo@ymail.com)

\begin{abstract}
Background. Gender-based violence (GBV), as a topic of medical study and practice, is an integral component of medical education in many developed countries. There is an increasing need to equip medical practitioners with appropriate knowledge, attitudes and skills to care for victims of GBV.

Objectives. To obtain consensus among stakeholders on content, the members of faculty who should teach the subject and the methods of training relating to GBV curricula in three medical schools in south-west Nigeria.

Methods. Three rounds of the Delphi technique involving 52 experts from among academics, medical practitioners, government and non-governmental organisations were conducted. The first round (RD 1) was open-ended, while subsequent rounds were structured. Consensus was defined as a gathering around mean $(>3.5)$ responses with minimal divergence (standard deviation (SD) $<1.5$ ) to the RD 2 questionnaire; strong consensus was $>4.0$. For the $\mathrm{RD} 3$, consensus was regarded as $>50 \%$ satisfaction with the rankings from RD 2 . A strong consensus was taken as $>60 \%$ satisfaction.

Results. Themes identified in RD 1 were: reasons for teaching GBV; teaching methods, strategies needed and departments best positioned to teach it; professions to involve in training; academic level to offer training; and strategies to assess effective training. From RD 2, the topics ranked highest for inclusion in training were (mean (SD)): complications of GBV, 4.44 (0.63); and safety plan, 4.44 (0.51). Offering training to final-year medical students was most preferred, at 4.25 (1.13); for teaching methods, using videos for training, at 4.63 (0.89), was ranked highest, followed by information, education and communication materials, at $4.50(0.82)$. Discussion with victims ranked highest as the most preferred format for teaching, followed by didactic lectures, at 4.06 (0.93) and 4.00 (0.89), respectively. The departments selected to teach GBV were Public Health, at 4.19 (0.91); Accidents and Emergency, 4.06 (0.85); Family Medicine, 3.81 (1.05); and Obstetrics and Gynaecology, 3.81 (0.89). Other professionals suggested were psychologists, social workers and lawyers. With regards to assessment, written examination ranked highest, at 4.06 (0.85). RD 3 confirmed the rankings of RD 2 on all themes, and sought additional suggestions for the training. Most (82.9\%) respondents had no additional suggestions; the few elicited included clarifying cultural misconceptions around GBV, involving religious leaders and psychologists, and the recommendation that the teaching should be sustained.

Conclusion. These results will inform the development of evidence-based competencies relevant to healthcare providers in the African context. The need for periodic review of the curricula of medical schools to ensure that they address patient and societal needs is highlighted.
\end{abstract}

Afr J Health Professions Educ 2018;10(2):106-113. DOI:10.7196/AJHPE.2018.v10i2.988

There is growing international consensus that health services need to respond to the needs of those experiencing abuse. ${ }^{[1]}$ There is also an increasing recognition of the need to equip medical practitioners with the appropriate knowledge, attitudes and skills to care for victims of intimate partner violence (IPV). Concerns have been raised that faculty possibly neglect teaching of the topic, as it is not included in medical curricula. ${ }^{[2]}$ It is therefore imperative to address this shortcoming in medical curricula, especially in low-income countries where traditions have supported and condoned levels of IPV. ${ }^{[3]}$ Different specialised groups of physicians are needed to care for women who have experienced IPV, when managing complications linked to abuse. ${ }^{[3]}$

Education about gender-based violence (GBV) in general offers a logical solution in addressing the problem of ignorance..$^{[4]}$ Education about violence has been integrated into medical schools, and is being taught by a variety of faculty in many high-income countries. ${ }^{[5,6]}$ Evaluations show that training on GBV and IPV generally improves the knowledge, attitudes and skills of students and clinicians ${ }^{[4]}$ However, medical faculty in many middle- and low-income countries are apprehensive about the complexities of addressing the topic. Apart from concerns over content and training methods, there is also a lack of agreement on the faculty best positioned to offer such training. ${ }^{[7,8]}$ Therefore these issues need consideration, to prepare a range of medical faculty to teach, serve and practise effectively in this area.

The present study was conducted to obtain consensus among interprofessional stakeholders on the content, methods and faculty to involve in educating and training medical students on GBV in south-west Nigeria. The study also explored reasons why stakeholders thought the teaching was necessary; it identified the stage in the curriculum best suited to teach the topic, and how to assess the effectiveness of training.

\section{Methods \\ Study design}

The Delphi technique ${ }^{[9]}$ was used to obtain consensus among experts on issues relating to the design of a GBV curriculum. Three rounds 
of questionnaires were circulated. The first round ( $R D$ 1) used openended questions; the next two rounds (RD 2 and 3) were structured. The responses from each round were summarised and reported to the stakeholders, who were then given an opportunity to respond in the subsequent round.

The questions in RD 1 asked whether GBV should be included in the curriculum. The questionnaire also explored the potential content and methods to be used, and asked experts about their previous training. The focus of RD 2 was to consolidate and validate suggestions on the content and methods generated by the RD 1 questionnaire. Stakeholders prioritised their responses by ranking each suggestion according to importance.

\section{Study setting}

The study was conducted in Lagos, Oyo and Osun states of south-west Nigeria in the medical schools of the University of Ibadan, the University of Lagos and the Ladoke Akintola University of Technology. In addition, relevant officials from the Ministries of Health and Women Affairs in the three states were invited as stakeholders. The three universities are public institutions, and all are affiliated to a teaching hospital.

\section{Selection of expert panel}

An expert was defined as a person with relevant knowledge of and experience in teaching about issues relating to GBV, with experience regarded as useful to inform the education of medical students. Four categories of experts were identified, and one academic, two medical practitioners, three government officials and four representatives of non-governmental organisations were included in the study.
The research team of two academic researchers and three medical practitioners, all familiar with issues relating to GBV in Nigeria, generated a list of nominees. They brainstormed and identified the most appropriate disciplines, organisations and literature to be used in identifying the categories of experts. ${ }^{[3,10]}$

\section{Invitation of experts}

Experts were contacted by telephone or in person and invited to participate. A detailed information sheet explaining the study purpose and procedures, including the level of commitment required, accompanied the RD 1 questionnaire. The participants were asked to complete and return the questionnaire within 5 days, but some had to be reminded repeatedly.

\section{Seeking consensus}

Consensus was defined as a gathering around mean responses with minimal divergence, which was taken as a mean score $\geq 3.5$, with a standard deviation of 1.5 or less, and consensus issues were included in the RD2 questionnaire. Very strong consensus was set at a mean $\geq 4.0$. For the RD 3 questionnaire, consensus was regarded as $>50 \%$ satisfaction with the rankings from RD 2 . A strong consensus was taken as $60 \%$ satisfaction with results from RD2, and very strong as $>70 \%$.

\section{Sample size}

The target was to obtain responses from 10 - 20 health professional experts from each site. A total of 52 experts participated in RD 1, 51 in RD 2 and 47 in RD 3 (Table 1).

\begin{tabular}{|c|c|c|c|}
\hline Variable & RD $1(N=52), n(\%)$ & RD $2(N=51), n(\%)$ & RD $3(N=47), n(\%)$ \\
\hline \multicolumn{4}{|l|}{ Medical school } \\
\hline Ibadan & $11(21.2)$ & $11(21.5)$ & $10(21.3)$ \\
\hline Lagos & $14(26.9)$ & $14(27.5)$ & $10(21.3)$ \\
\hline Osogbo & $27(51.9)$ & $26(51.0)$ & $27(57.4)$ \\
\hline \multicolumn{4}{|l|}{ Age (years) } \\
\hline $20-29$ & $1(2.0)$ & $1(2.0)$ & $1(2.1)$ \\
\hline $30-39$ & $15(28.8)$ & $18(35.3)$ & $14(29.8)$ \\
\hline $40-49$ & $28(53.8)$ & $27(52.9)$ & $23(48.9)$ \\
\hline $50-59$ & $8(15.4)$ & $5(9.8)$ & $9(19.2)$ \\
\hline \multicolumn{4}{|l|}{ Sex } \\
\hline Male & $22(42.3)$ & $23(45.1)$ & $2(44.7)$ \\
\hline Female & $30(57.7)$ & $28(52.9)$ & $26(55.3)$ \\
\hline \multicolumn{4}{|l|}{ Organisation } \\
\hline Academics/practitioners & $42(80.8)$ & $42(82.4)$ & $41(87.2)$ \\
\hline Ministry of Health/Women Affairs & $6(11.5)$ & $5(9.8)$ & $4(8.5)$ \\
\hline Non-governmental organisation & $4(7.7)$ & $4(7.8)$ & $2(4.3)$ \\
\hline Medical specialty & $(n=48)$ & $(n=47)$ & $(n=47)$ \\
\hline Accidents and emergency & $4(8.3)$ & $5(10.6)$ & $4(8.5)$ \\
\hline Dental surgery & $3(6.3)$ & $3(6.4)$ & $3(6.4)$ \\
\hline Family medicine & $5(10.4)$ & $5(10.6)$ & $5(10.6)$ \\
\hline Obstetrics and gynaecology & $7(14.6)$ & $8(17.0)$ & $7(14.9)$ \\
\hline Paediatrics & $4(8.3)$ & $4(8.5)$ & $2(4.3)$ \\
\hline Public health/ community medicine & $12(25.0)$ & $11(23.4)$ & $6(12.8)$ \\
\hline Psychiatry & $3(6.3)$ & $3(6.4)$ & $4(8.5)$ \\
\hline Other ${ }^{*}$ & $10(20.8)$ & $8(17.1)$ & $16(34.0)$ \\
\hline
\end{tabular}




\section{Research}

\section{Questionnaire development}

$\mathrm{RD}$ 1: The RD 1 questionnaire was developed after an extensive literature review $^{[5-11]}$ based on the results of our previous study with medical students and faculty in one of the institutions. ${ }^{[2]}$ The questionnaire consisted of 11 items, and was open-ended. It solicited information on reasons why courses on GBV issues should be taught (Table 2); the academic level at which they should be taught; the content to be covered (Table 3); teaching methods and strategies; contact hours; duration; format; which medical department(s) should do the teaching; other health professionals to involve in teaching; and suitable teaching platforms to explore. The experts were also asked if they had prior experience in teaching and/or managing patients/victims of GBV, and whether they would share their material.

$\mathrm{RD}$ 2: The RD 2 questionnaire was developed after analysis of the RD 1 results. The RD 2 questionnaire ranked the 12 themes identified from the
RD 1 questionnaire on a 5-point scale, in order of importance, from 5 as most important to 1 as least important. The themes were summarised as follows: the reasons why GBV issues should be taught; medical/clinical and other professionals to include in the training; content and teaching strategies to use; and the academic levels at which to offer training. The results of the ranking are shown in Table 4.

$\mathrm{RD}$ 3: The RD 3 questionnaire informed participants of the results received on each variable of the 12 themes in RD 2. Stakeholders were asked to comment on the results, and to suggest additional items that they might not have considered initially, and/or make changes to earlier responses.

\section{Data collection}

Data collection was preceded by telephone calls to the experts by the principal investigator; next, a member of the research team made physical visits to the

Table 2. Reasons for GBV issues to be taught at medical schools

\begin{tabular}{ll}
\hline Area of concern & Quote \\
\hline Students & 'To prepare them to recognise and handle GBV cases.' \\
& 'To empower them to recognise potential victims.' \\
& 'To create awareness of GBV among medical students.'
\end{tabular}

GBV as a problem 'To promote enlightenment for prevention of GBV'

'It makes them know what constitutes GBV as some of them perpetrate without knowing.'

Community 'Most people don't really know what GBV is.'

'It's the paradigm shift all over the world, it will ensure a better nation.'

Victims

'To break [the] culture of silence on the issue. Silence by female victims [is] common.'

'They will be able to do some counselling of the victims.'

$\mathrm{GBV}=$ gender-based violence; $\mathrm{O} \& \mathrm{G}=$ obstetrics and gynaecology; $\mathrm{YWE}=$ years of work experience

\section{Participant characteristics}

40 - 49 years, male, Lagos, community medicine, 0 - 9 YWE

50 - 50 years, male, Ibadan, O\&G, consultant/lecturer, $\geq 20$ YWE

40 - 49 years, male, Lagos, ophthalmology, senior lecturer, 10 - 19 YWE

40 - 49 years, male, Ibadan, family medicine, consultant, 10 - 19 YWE

40 - 49 years, male, Lagos, public health, consultant/lecturer, 10 19 YWE

20 - 29 years, female, Lagos, accidents and emergency, medical officer, 0 - 9 YWE

30 - 39 years, female, Osogbo, dentist, dental officer, 0 - 9 YWE

30 - 39 years, female, Osogbo, Ministry of Women Affairs, gender officer, 0 - 9 YWE

40 - 49 years, male, Lagos, family medicine, consultant, $\geq 20$ YWE
Table 3. Topics to include in a GBV training programme

\section{Topic \\ 'Epidemiology of GBV; identification and understanding signs of GBV'}

'Causes of GBV; types of GBV; medico-legal view of GBV'

'Types of GBV; prevalence of GBV; identification of victims of GBV'

'Risk factors, causes, management of GBV and the local and national laws on GBV'

'GBV and culture; societal responsibilities to GBV victims'

'Female genital cutting and widow inheritance'

'Ethics of managing GBV and policy issues around GBV'

'Measurement issues in GBV'

'Understanding the mind of perpetrators, including forensics and jurisprudence of GBV'

\section{Participant characteristics}

40 - 49 years, female, Lagos, community medicine, senior lecturer, 0 - 9 YWE

40 - 49 years, male, Ibadan, family medicine, consultant, $>20$ YWE

50 - 59 years, female, Ibadan, community medicine, senior lecturer, 10 - 19 YWE

40 - 49 years, female, Osogbo, paediatrics, consultant, 10 - 19 YWE

40 - 49 YWE, female, Osogbo, family medicine, consultant/ lecturer, 0 - 9 YWE

20 - 29 years, female, Lagos, paediatrician, consultant, 0 - 9 YWE

50 - 59 years, male, Ibadan, community medicine, lecturer/ public health physician, 10 - 19 YWE

50 - 59 years, male, Lagos, O\&G, senior lecturer, 10 - 19 YWE

40 - 49 years, male, Ibadan, oral pathology, lecturer/ consultant, 10 - 19 YWE 


\section{Research}

Table 4. Ranking of categories for the training curriculum by participants

\begin{tabular}{|c|c|c|}
\hline Categories & Responses received & Mean (SD) \\
\hline \multicolumn{3}{|c|}{ Reasons why GBV should be taught } \\
\hline & Awareness of GBV & $4.56(0.63)$ \\
\hline & Prevention and control & $4.44(0.81)$ \\
\hline & Support or counsel victims & $4.44(0.81)$ \\
\hline & Refer to where to seek help & $4.44(0.81)$ \\
\hline & Identify/screen GBV cases & $4.19(1.05)$ \\
\hline & Preparedness to treat GBV cases & $4.13(1.09)$ \\
\hline \multicolumn{3}{|c|}{ Content of GBV training for the students } \\
\hline & Prevention and safety & $4.44(0.51)$ \\
\hline & Complications & $4.44(0.63)$ \\
\hline & Medical/legal aspect of violence & $4.38(0.60)$ \\
\hline & Signs and symptoms & $4.38(0.72)$ \\
\hline & Role of physicians in GBV control & $4.38(0.80)$ \\
\hline & Risk factors of GBV & $4.31(0.70)$ \\
\hline & Causes of GBV & $4.31(0.79)$ \\
\hline & Types of GBV & $4.31(0.95)$ \\
\hline & Ethical issues, e.g. confidentiality etc. & $4.25(0.93)$ \\
\hline & Management of victims & $4.19(0.66)$ \\
\hline & Gender equality & $4.19(1.17)$ \\
\hline & Definition of GBV & $4.13(0.89)$ \\
\hline & Prevalence/epidemiology & $4.13(0.19)$ \\
\hline & Identification of victims & $4.13(1.03)$ \\
\hline \multicolumn{3}{|c|}{ Strategies for teaching GBV } \\
\hline & Video - documentaries, clips & $4.63(0.89)$ \\
\hline & IEC material - posters, flyers, charts & $4.50(0.82)$ \\
\hline & PowerPoint presentation & $4.19(0.98)$ \\
\hline & Web-based/internet & $4.06(0.85)$ \\
\hline & Skills training & $3.94(0.93)$ \\
\hline & Case-based learning & $3.94(1.06)$ \\
\hline & Role play & $3.75(1.13)$ \\
\hline & Didactic lectures & $3.75(1.54)$ \\
\hline \multicolumn{3}{|c|}{ Level/year GBV should be taught } \\
\hline & 600 & $4.25(1.13)$ \\
\hline & 500 & $3.88(1.09)$ \\
\hline & 400 & $3.44(1.03)$ \\
\hline & 300 & $3.13(1.26)$ \\
\hline & 200 & $2.69(1.54)$ \\
\hline & 100 & $2.69(1.54)$ \\
\hline \multicolumn{3}{|c|}{ Duration of GBV training } \\
\hline & Longitudinal & $3.88(1.26)$ \\
\hline & Periodic & $3.81(1.17)$ \\
\hline & Once & $2.19(1.22)$ \\
\hline \multicolumn{3}{|c|}{ Contact hours } \\
\hline & 4 hours & $3.25(1.4)$ \\
\hline & 2 hours & $3.19(1.8)$ \\
\hline & $>4$ hours & $2.94(1.6)$ \\
\hline \multicolumn{3}{|c|}{ Formats for teaching } \\
\hline & Discussion with victims & $4.06(0.89)$ \\
\hline & Didactic lectures & $4.00(0.93)$ \\
\hline & Bedside teaching & $3.69(1.49)$ \\
\hline & Case study/presentation report & $3.88(1.26)$ \\
\hline \multicolumn{3}{|c|}{ Departments well positioned to teach } \\
\hline & Community medicine & $4.19(0.91)$ \\
\hline & Accidents and emergency & $4.06(0.85)$ \\
\hline & Public health & $4.06(0.93)$ \\
\hline
\end{tabular}




\section{Research}

\begin{tabular}{|c|c|c|}
\hline Categories & Responses received & Mean (SD) \\
\hline & Obstetrics and gynaecology & $3.81(0.89)$ \\
\hline & Family medicine & $3.81(1.05)$ \\
\hline & Psychiatry & $3.56(1.21)$ \\
\hline & Dentistry & $3.19(1.42)$ \\
\hline \multicolumn{3}{|c|}{ Other professionals who can teach } \\
\hline & Psychologist & $4.19(0.98)$ \\
\hline & Social worker & $4.13(1.02)$ \\
\hline & Nurse & $3.94(0.99)$ \\
\hline & Lawyer & $3.81(0.83)$ \\
\hline & Counsellor & $3.81(1.11)$ \\
\hline & Sociologist & $3.81(1.11)$ \\
\hline & Paediatrician & $3.44(1.41)$ \\
\hline \multicolumn{3}{|c|}{ Why other professionals should teach } \\
\hline & Multidisciplinary & $4.38(0.81)$ \\
\hline & Intersectoral & $4.31(0.79)$ \\
\hline & Social problem & $4.23(0.86)$ \\
\hline \multicolumn{3}{|c|}{ Venue to teach GBV } \\
\hline & Hospital & $4.38(0.95)$ \\
\hline & Community & $4.38(0.96)$ \\
\hline & Classroom & $4.31(0.79)$ \\
\hline \multicolumn{3}{|c|}{ Assessment methods on GBV } \\
\hline & Written examination & $4.06(0.85)$ \\
\hline & Term paper (assignment) & $3.75(1.07)$ \\
\hline & Oral examination & $3.63(1.03)$ \\
\hline & Clinical examination & $3.56(0.89)$ \\
\hline
\end{tabular}

experts to distribute the information sheet and questionnaire. The study instruments and information sheets were pretested on five resident doctors from the University College Hospital, Ibadan, and necessary adjustments were made before data collection commenced. The Delphi questionnaires were hand-delivered to participants, and collected a few days later by a research assistant. Each round was accompanied by an information sheet, which in $\mathrm{RD} 1$ introduced and explained the study to respondents under the following subheadings: What is a Delphi study? What is the purpose of the study? Why have I been invited to take part? What will I be asked to do if I take part? Who is organising the research? How will confidentiality be maintained? What do I do now? How do I contact the principal investigator?

The information sheet used in RD 2 provided feedback on the results of the previous $\mathrm{RD}$, and it was modified to suit $\mathrm{RD} 3$ of the study.

RD 1 data collection occurred between June and July 2016. The RD 1 questionnaire took approximately 30 minutes to complete. RD 2 data collection took place between August and October 2016, while RD 3 commenced in November 2016 and ended in January 2017. RD 2 took about 15 minutes to complete, and $\mathrm{RD}$ 3, 20 minutes. The data collection was conducted by three trained resident doctors, who were assisted with retrieval of the completed questionnaires by a research assistant.

\section{Data analysis}

The three rounds were analysed using different methods.

$\mathrm{RD} 1$ : The data generated from the open-ended questions in $\mathrm{RD} 1$ were coded. Data were entered into Statistical Package for Social Sciences (SPSS;
IBM Corp., USA) version 16 and analysed using Excel (Microsoft, USA). These open-ended, qualitative data were coded and categorised in response to each research question.

RD 2: The data were entered and analysed using SPSS version 16. Means and standard deviations (SDs) were calculated for all responses. Each mean was used to obtain a numerical indication of the overall support for a statement, where the responses to the statements were measured on a scale from 1 (least important) to 5 (most important). Mean values between 2 and 3 were interpreted as uncertainty or indicating no consensus, while $\geq 3.5$ and $\leq 1$ indicated clear positive and negative consensus, respectively. The SD provided a measure of the dispersion of the responses. A small SD between 0.1 and 1.5 was interpreted as indicating greater certainty and consensus on the item being measured.

$\mathrm{RD}$ 3: The data obtained were coded and entered into SPSS version 16, and analysed using Excel. Respondents' level of satisfaction with the results generated was described in percentages, while quotes on suggestions were collected.

\section{Ethical considerations}

The study was a low-risk project; however, ethical clearance was obtained from the Ethical Review Committee of the Oyo State Ministry of Health (ref. no. AD13/479/165) and the University College Hospital Institutional Review Board (ref. no. UI/EC/15/03/11). The purpose of the study was explained to participants, and verbal informed consent obtained. Stakeholders were assured of confidentiality and anonymity, and identifying details were not recorded on the questionnaires. Responses were kept confidential. The 
completed questionnaires were kept in a secure compartment in the custody of the main investigator. The investigators had no conflict of interest and the results did not influence their work in any way. Data were entered into a password-protected computer.

\section{Results \\ Round 1 results}

\section{Sociodemographic characteristics of experts}

A total of 52 expert participants participated in RD 1. A little over half (53.8\%) of the experts were between 40 and 49 years of age. There was a slight female preponderance (57.7\%). Most (80.8\%) participants were from a university or hospital, while the others represented government ministries and non- governmental organisations. The medical specialties of those from training institutions cut across 11 disciplines, including preventive medicine $(25.0 \%)$, obstetrics and gynaecology (14.6\%), paediatrics $(8.3 \%)$ and accident and emergency (8.3\%). Regarding years of work experience, 44.2\% had worked for between 10 and 19 years (Table 1).

\section{Categories generated}

In response to $\mathrm{RD} 1$, eight categories were identified for teaching about GBV issues. These were regrouped into five categories (A - E).

A. Reasons why GBV issues should be taught at medical schools: Stakeholders gave reasons why GBV should be included in the medical undergraduate curriculum. The responses, as illustrated by the quotes in Table 2, focused mainly on four areas of concern, namely preparedness of students, the effect of GBV on health, and its effects on the community and on the victims. Concern was expressed that students should become knowledgeable and skilled. There was also concern to improve awareness of GBV as a public health problem, as it was believed that its inclusion in medical curricula would reduce its prevalence in the community, and providing training to students would improve the protection and treatment for victims.

B. Teaching methods, strategies/resources needed and department best positioned:

B1. Topics to include in a GBV training programme: Stakeholders proposed several topics to include in the curriculum, namely causes of GBV, signs and symptoms, complications, types of GBV, and management of GBV cases (Table 3). Some experts proposed the inclusion of contemporary and culture-specific topics.

B2. Teaching strategies for GBV: The strategies identified as most useful included didactic lectures, seminar/small group discussions, case studies, students' presentations of group work and student-driven research projects on GBV. According to some participants:

'Didactic lectures, discussion format, group work for presentation and research' (30 - 39 years, female, lecturer/public health physician, Lagos: 10 - 19 YWE)

'Topics can be incorporated into core lectures, followed by case studies and group discussions, clinical clue ship, observer ship, and term paper/ essay' (40 - 49 years, female, emergency medicine, consultant physician, Ibadan, 10 - 19 YWE)

B3. Format for teaching: Stakeholders suggested using didactic lectures, supplemented by video documentaries, information, education and communication materials and case studies, as a possible teaching format:
'Didactic lectures, true cases, case studies, skills training' (40 - 49 years, female, clinical pathology, consultant pathologist, Ibadan, 0 - 9 YWE)

'Didactic lectures, true cases, case studies' (30 - 39 years, male, obstetrics and gynaecology, senior registrar, Osogbo, 0 - 9 YWE).

C. Teachers:

C1. Other professionals who can teach on GBV: Apart from medical practitioners, other professionals suggested who could teach on GBV included psychologists, sociologists, lawyers, nurses and social workers. For example, some participants suggested:

'Psychologist' (30 - 39 years, female, internal medicine, consultant physician, Lagos, 10 - 19 YWE)

'Sociologist' (40 - 49 years, male, community health, senior lecturer, Lagos, 10 - 19 YWE)

'Social workers' (30 - 39 years, female, dental surgery, dental officer, Osogbo, 0 - 9 YWE).

C2. Reasons why other professionals should teach GBV: The experts motivated for teaching by other health professionals, describing GBV as a social, multidisciplinary and multidimensional problem. According to these stakeholders:

'There are various aspects to GBV, it requires multidisciplinary approach' (40 - 49 years, male, oral pathology, lecturer/consultant, Ibadan, 10 - 19 YWE)

'GBV is a social problem that needs to be tackled by all' (30 - 39 years, female, Women Department official, gender officer, Osogbo, 0 - 9 YWE)

\section{C3. Previous teaching experience on GBV}

Ten experts (19.2\%) had prior teaching experience in GBV and had taught medical students on managing patients/victims of GBV. Seven (70\%) of these experts were willing to share their materials with other teachers.

D. Academic level(s) of medical students to whom training should be offered, and number of contact hours suggested by experts: The experts had various suggestions on year of schooling. These included:

'Clinical years' (30 - 39 years, female, consultant, obstetrics and gynaecology, Osogbo, 10 - 19 YWE)

'400 - 600 levels' (30 - 39 years, male, senior registrar, psychiatry, Lagos, 1 - 9 YWE)

On the number of contact hours, one participant (40 - 49 years, female, community health, lecturer I, Lagos, 10 - 19 YWE) suggested two, while another (40 - 49 years, male, Institute of Child Health, senior research fellow, Ibadan, 0 - 9 YWE) suggested four.

E. Strategies to assess the impact and effectiveness of the training: Written examinations were recommended by one participant (40 - 49 years, female, clinical pathology, consultant, Lagos, 0 - 9 YWE), while another (60 years, male, surgery, senior lecturer, Lagos, 10 - 19 YWE) suggested clinical examination.

\section{Round 2 results}

The highest-ranked reason for implementing teaching on GBV (4.56 (0.63)) was to increase awareness. Additional reasons selected were to provide support to victims; to prevent and control violence; and to appropriately 
refer patients for care $(4.44(0.81$ each $))$. As shown in Table 4 , the 14 suggested topics for content of the GBV programme all ranked above 4.00. The highest-ranked topics were complications of GBV (4.44 (0.63)) and safety plans $(4.44(0.51))$, and the least the definition (4.13 (0.89)), prevalence (4.13 (0.19)) and identification of victims (4.13 (1.03)).

Stakeholders preferred training to be offered to the most mature students, i.e. at final-year level (4.25 (1.13)). The preferred teaching strategies included videos (documentaries and clips; 4.63(0.89)) and the use of information, education and communication materials (4.50 (0.82)). Allocating 4 contact hours to teaching was the most preferred option $(3.25$ (1.4)) among the experts.

A longitudinal training programme was preferred over once-off training (3.88 (1.26) v. 2.19 (1.22)). The experts ranked discussions with victims as the most preferred strategy, followed by didactic lectures and case studies (4.06 (0.93), $4.00(0.89)$ and 3.88 (1.26), respectively (Table 4).

The medical departments considered best positioned to teach GBV were those dealing with community medicine $(4.19(0.91))$, public health $(4.06$ (0.93)), accidents and emergency (4.06 (0.85)), family medicine (3.81 (1.05)), obstetrics and gynaecology (3.81 (0.89)), and psychiatry (3.56 (1.21)). Dentistry was the least preferred $(3.19(1.42))$. The multidimensional nature of GBV was the main reason (4.38 (0.81)) for including other professionals in the teaching, followed by 'it is a social problem' $(4.23(0.86))$. Other professionals identified included psychologists $(4.19(0.98))$, social workers (4.13 (1.02)) and nurses (3.94 (0.99)). Teaching platforms included hospitals (wards and clinics, $4.38(0.96))$, community $(4.38(0.96))$ and classrooms (4.31 (0.79)).

A written examination ranked highest $(4.06(0.85))$ as the preferred method to assess students' learning on GBV.

\section{Round 3 results}

Most ( $>60 \%$, depending on the theme) stakeholders were satisfied with the rankings from $\mathrm{RD} 2$. There was consensus (Table 5) on the strategies for teaching on GBV (83.0\%) and reasons why it should be taught (89.3\%). Most disagreement related to the 'format' (23.4\%), 'venue' for teaching (23.4\%) and the 'duration of the training' (34.0\%). The comments were, however, positive and affirmed a need for continuous and synchronised training, rather than irregular sessions, with preference shown for 2 contact hours per module. The Department of Public Health was indicated as being the best positioned to offer a course (Table 5).
The majority of all the stakeholders (82.9\%) offered no suggestions on how to improve training on GBV. However, some respondents suggested clarifying cultural misconceptions around GBV (4.3\%); the involvement of religious leaders (4.3\%) and psychologists in teaching (2.1\%); using midand end-of-term assessments (2.1\%); and that training should be sustained (4.3\%).

\section{Discussion}

This study was conducted to obtain consensus among stakeholders on the necessary content and teaching methods for a GBV curriculum at 3 medical schools in Nigeria. Most of the experts surveyed, representing the 3 states, were based at training institutions. However, they represented various disciplines, indicating some consensus on the multidisciplinary nature of the problem and interdisciplinary dimensions needed to address IPV as a curricular topic. Only a few participants represented the relevant government ministries and non-governmental organisations. This is not surprising, as GBV has only recently started to receive government attention in Nigeria, despite the country having been a signatory to international treaties and declarations on women's rights for more than a decade. ${ }^{[12]} \mathrm{IPV}$ in particular in many low- and middle-income countries is often shrouded in secrecy, which inhibits victims from open discussions of abuse. ${ }^{[13]}$

Most of the reasons for introducing GBV into the medical curriculum centred on students' training needs, and an awareness of the need to address the issue in the community and to help victims of GBV. The benefit of improved awareness created by training on GBV was highly favoured. Participants preferred a structured curriculum for its ability to provide evidence-based and scientific information, ${ }^{[14]}$ which is more likely to be factual, comprehensive and acceptable to healthcare practitioners and students. ${ }^{[15]}$

Training on the prevention and complications of GBV were considered important, to enable students, as practitioners, to identify and manage victims appropriately. Training on the signs and symptoms of GBV, with the appropriate knowledge and skills to identify victims, was also considered important. Several instruments are used by healthcare providers to identify victims of GBV in healthcare settings. The instruments target different categories of victims, such as women, men, pregnant women or women attending special clinics, and paediatric patients. The instruments also cater for self-reporting, while clinician-administered or computer-based instruments are also used. ${ }^{[16]}$ Stand-alone didactic lectures were not the most

Table 5. Consensus on content and methods of a GBV curriculum

\begin{tabular}{lllll}
\hline Theme & $\begin{array}{l}\text { Satisfied with ranking, } \\
\text { frequency (\%) }\end{array}$ & $\begin{array}{l}\text { Gave some other } \\
\text { options, frequency (\%) }\end{array}$ & $\begin{array}{l}\text { No response, } \\
\text { frequency (\%) }\end{array}$ & Total, frequency (\%) \\
\hline Reason why GBV should be taught & $42(89.3)$ & $1(2.1)$ & $4(8.5)$ & $47(100.0)$ \\
Strategies for teaching GBV & $39(83.0)$ & $2(4.3)$ & $6(12.8)$ & $47(100.0)$ \\
Content of GBV training for student & $37(78.7)$ & $4(8.5)$ & $6(12.8)$ & $47(100.0)$ \\
Other professionals who can teach GBV & $32(68.1)$ & $5(10.6)$ & $10(21.3)$ & $47(100.0)$ \\
Level/year GBV should be taught & $30(63.8)$ & $11(23.4)$ & $6(12.8)$ & $47(100.0)$ \\
Format for teaching & $30(63.8)$ & $6(12.8)$ & $11(23.4)$ & $47(100.0)$ \\
Reasons other professionals should teach GBV & $31(66.0)$ & $7(14.9)$ & $9(19.1)$ & $47(100.0)$ \\
Venue to teach GBV & $31(66.0)$ & $5(10.6)$ & $11(23.4)$ & $47(100.0)$ \\
How training should be assessed & $29(61.7)$ & $9(19.1)$ & $9(19.1)$ & $47(100.0)$ \\
Department in best position to teach & $28(59.6)$ & $11(23.4)$ & $8(17.0)$ & $47(100.0)$ \\
Contact hours & $24(51.1)$ & $15(31.9)$ & $8(17.0)$ & $47(100.0)$ \\
Duration of GBV training & $22(46.8)$ & $16(34.0)$ & $9(19.2)$ & $47(100.0)$ \\
GBV = gender-based violence. & & & &
\end{tabular}


preferred format for training, but the experts in our study recognised their value in complementing visual materials to enhance learning, as has been reported in a previous study. ${ }^{[17]}$

The experts did not reach a clear consensus on the duration of training necessary, possibly owing to the varying lengths of medical degrees at the three medical schools, and the variable ability to accommodate curricular additions. ${ }^{[1]}$ It is also possible that experts differ across the disciplines on the number of hours necessary to dedicate to the topic, and that these decisions require further discussions before the start of a programme.

There was strong consensus and agreement on the departments that should offer the training. The departments of community medicine and public health were preferred, suggesting a recognition of GBV as a major public health concern. ${ }^{[18]}$ The department of accidents and emergency was preferred over obstetrics and gynaecology, which is surprising considering that GBV can result in a number of reproductive health complications in women. Studies have been conducted on GBV among physicians in both these specialties. ${ }^{[19,20]}$

Many stakeholders appreciated the emotional problems that may arise following an episode of violence, and recommended the inclusion of a psychologist on the training team. Mental health complications following abuse, including anxiety disorders, depression, low self-esteem, posttraumatic stress and substance abuse have been reported previously. ${ }^{[21,22]}$ Stakeholders considered the social constructs surrounding GBV, and the need for practical safety plans for victims and their children, including support from social services. Involving social-work practice in student training on GBV would provide comprehensive services to promote women's health and safety, and to foster social principles of meeting clients at their points of need. ${ }^{[23}$ As found in our study, prior studies have also identified the teaching role of nurses. Tuft et al. ${ }^{[24]}$ similarly recommended the training of nurses as educators on GBV, while legal practitioners can advise on laws to protect victims. ${ }^{[25]}$ Assessment is crucial, as it drives learning, ${ }^{[26]}$ and the training institutions agreed that they needed further in-house deliberations on the best assessment practices, for consideration at each university.

The strength of this study lies in the use of the Delphi technique, which allows for repeated iterations on the content and format with the experts. The main limitations related to the fact that most experts represented academia, and to the attrition in later rounds. Despite attempts, few experts were available to participate from government and non-governmental organisations, owing to industrial action in two states at the time of study. Secondly, there was no response or consensus to some themes presented in RD 3, which could be viewed as indicating either satisfaction with or a lack of interest in the theme. Despite this shortcoming, the results still provide information useful for the development of a curriculum on GBV in the medical schools. It may also be possible to generalise the findings to other medical schools in Nigeria.

It is recommended that an interdisciplinary and transdisciplinary approach be followed, to design a GBV curriculum to address issues relating to GBV in medical schools in the region.

\section{Conclusion}

Consensus was reached on the content, methods and faculty necessary for training medical students on GBV in south-west Nigeria. There was agreement on the disciplines best suited to teach such a programme, and the need to assess the training. Further discussions are needed per institution on the appropriate contact hours, duration of training and particular disciplines to involve in the training. The results will inform the development of evidencebased competencies relevant to healthcare providers in the African context.

Acknowledgements. We thank the GBV experts for their time and responses. Author contributions. Conception and design: OIF, JvW; administrative support: OIF; data collection: BOB, AA, OJA; data analysis and interpretation: OIF, JvW; manuscript writing: OIF, JVW. All authors read and approved the final manuscript. Funding. Data collection was funded by the University of KwaZulu-Natal, Durban, South Africa.

Conflicts of interest. None.

1. World Health Organization. Responding to Intimate Partner Violence and Sexual Violence against Women WHO Clinical and Policy Guidelines. Geneva: WHO, 2013.

2. Fawole OI, van Wyk J, Adejimi A. Training needs on violence against women in the medical curriculum at the University of Ibadan, Nigeria. Afr J Health Professions Educ 2013;5(2):75-79. https://doi.org/10.7196/AJHPE.22 3. Mork T, Andersen PT, Taket A. Barriers among Danish women and general practitioners to raising the issue of intimate partner violence in general practice: A qualitative study. BMC Women’s Health 2014;14:74. https://doi org/10.1186/1472-6874-14-74

4. Hamberger LK. Preparing the next generation of physicians: Medical school and residency-based intimate partner violence curriculum and evaluation. TVA 2007;8(2):214-225. https://doi.org/10.1177/1524838007301163 5. Connor PD, Nouer SS, Mackey SN, Banet MS, Tipton NG. Intimate partner violence education for medical students: Toward a comprehensive curriculum revision. South Med I 2012;105(4):211-215. https.//dol org/10.1097/SMJ.0b013e31824f8b01

6. Hussain N, Sprague S, Madden K, Hussain FN, Pindiprolu B, Bhandari M. A comparison of the types of screening tool administration methods used for the detection of intimate partner violence: A systematic review and metatool administration methods used for the detection of intimate partner violence: A systematic reser

7. Hossain N, Khan S. Domestic abuse and the duties of physicians: A case report. Indian J Med Ethics Hossain N, Khan S. Domestic abuse and the duties of phys
2015;12(4):248-250. https://doi.org/10.20529/IIME.2015.066

2015;12(4):248-250. https://doi.org/10.20529/IJME.2015.066 8. Kamimura A, Al-Obaydi S, Nguyen H, et al. Intimate partner violence education for medical students in the
Vietnam and China. Public Health 2015;129(11):1452-1458. https://doi.org/10.1016/j.puhe.2015.04.022

9. Okoli C, Pawlowski SD. The Delphi method as a research tool: An example, design considerations and applications. Inf Manag 2004;42(2):15-29. https://doi.org/10.1016/j.im.2003.11.002

10. Rasoulian M, Shirazi M, Nojomi M. Primary health care physicians' approach toward domestic violence in Tehran, Iran. Med J Islam Repub Iran 2014;28(148):1-8,

11. Usta J, Hlais S, Farhat HA, Romani M, Bzeih H, Abdo L. Lebanese medical students' exposure to domestic violence: Does it affect helping survivors? Fam Med 2014;46(2):112-119.

12. Federal Republic of Nigeria. National Gender Policy: Situation Analysis/Framework. Abuja: Federal Republic of Nigeria, 2006.

13. World Health Organization. Preventing Intimate Partner and Sexual Violence against Women: Taking Action and Generating Evidence. Geneva: WHO, 2010. https://doi.org/10.1136/ip.2010.029629

14. Feder GS, Hutson M, Ramsay J, Taket AR. Women exposed to intimate partner violence. Expectations and Feder GS, Hutson M, Ramsay J, Taket AR. Women exposed to intimate partner violence. Expectations and
experiences when they encounter health care professionals: A meta-analysis of qualitative studies. Arch Intern Med 2006;166(1):22-37. https://doi.org/10.1001/archinte.166.1.22

15. Wathen CN, Tanaka M, Catallo C, et al. Are clinicians being prepared to care for abused women? A survey of health professional education in Ontario, Canada. BMC Med Educ 2009;9(34). https://doi.org/10.1186/1472 6920-9-34

16. Basile KC, Hertz MF, Back SE. Intimate Partner Violence and Sexual Violence Victimization Assessment Instruments for Use in Healthcare Settings: Version 1. Atlanta (GA): Centers for Disease Control and Prevention National Center for Injury Prevention and Control, 2007.

17. Buranosky R, Hess R, McNeil MA, Aiken AM, Chang JC. Once is not enough: Effective strategies for medical student education on intimate partner violence. Violence Against Women 2012;18(10):1192-1212. https://doi. org $/ 10.1177 / 1077801212465154$

18. Centers for Disease Control. Intimate partner violence: Fact sheet, 2006. Atlanta: CDC, 2006. http:/www.cdc.gov/ ncipc/factsheets/ipvfacts.html (accessed 29 September 2015)

19. Ball CA, Kurtz AM, Reed T. Evaluating violent person management training for medical students in an emergency medicine clerkship. South Med J 2015;108(9):520-3. https://doi.org/10.14423/SMJ.0000000000000337

20. Farchi S, Polo A, Asole S, Ruggieri MP, Di Lallo D. Use of emergency department services by women victims of violence in Lazio region, Italy. BMC Women's Health 2013;13:31. https://doi.org/10.1186/1472-6874-13-31

21. Fawole OI, Abass LW, Fawole AO. Prevalence of violence against pregnant women in Ibadan, Nigeria. Afr J Med Med Sci 2010;39(4):293-303.

2. Fawole OI, Aderonmu AL, Fawole AO. Intimate partner abuse: Wife beating among civil servants in Ibadan, Nigeria. Afr J Reprod Health 2005:54-64.

23. Petrosky M, Colaruotolo LA, Billings RJ, Meyerowitz C. The integration of social work into a postgraduate dental training program: A fifteen-year perspective. J Dental Educ 2009;73(6):656-664.

24. Tufts KA, Clements PT, Karlowicz KA. Integrating intimate partner violence content across curricula Developing a new generation of nurse educators. Nurse Educ Today 2009;29(1):40-47. https://doi.org/10.1016/j. nedt.2008.06.005

25. Fawole OI, Ajuwon AJ, Osungbade KO. Evaluation of interventions to prevent gender-based violence among young female apprentices in Ibadan, Nigeria. Health Educ 2005;105(3):186-203. https://doior $10.1108 / 09654280510595254$

26. Glick S. Domestic violence simulated patient case. MedEdPORTAL 2007;3:624. https://doi.org/10.15766/ mep_2374-8265.624

Accepted 15 January 2018 